\title{
Alaska's Next Generation of Potential Fishermen: a Survey of Youth Attitudes Towards Fishing and Community in Bristol Bay and the Kodiak Archipelago
}

\author{
Jesse Coleman ${ }^{1}$ (D) $\cdot$ Courtney Carothers ${ }^{2} \cdot$ Rachel Donkersloot $^{3} \cdot$ Danielle Ringer $^{4} \cdot$ Paula Cullenberg $^{5}$. \\ Alexandra Bateman ${ }^{6}$
}

Received: 8 March 2018 / Accepted: 29 August 2018 / Published online: 14 September 2018

(C) The Author(s) 2019, corrected publication April 2019

\begin{abstract}
Commercial fishery participants in Alaska are increasing in age, and the next generation of fishermen faces numerous, complex barriers to entry into the industry. Although these barriers are now widely recognized, what remains to be seen is whether or not the youngest generation of coastal residents will choose place-based fishing livelihoods. In this study, we surveyed seventh through 12th grade students in the fishery-dependent Bristol Bay and Kodiak Archipelago regions of Alaska to explore what factors best predict students' attitudes about commercial fishing and their communities. We used multinomial logit models of Likert-scale responses predicted by geographic, demographic, and social variables, as well as conditional inference trees to understand the direction, magnitude, and importance of the relationships among the predictor and response variables. Positive attitudes about fishing were best predicted by student experience in the commercial fishing industry, whether the student wanted to be involved in fishing in the future, and the importance of subsistence fishing to the student's family. Age, how the student felt about their life, the importance of subsistence activities, and whether the student grew up in the community in which they were surveyed were all strongly related to the student's positive attitude about their community. Youth surveyed in this study were highly uncertain about their futures, but key periods of exposure through community and family ties to fishing emerged as important mechanisms for engagement among the next generation of potential fishermen.
\end{abstract}

Keywords Commercial fisheries $\cdot$ Rural youth $\cdot$ Alaska $\cdot$ Barriers to entry $\cdot$ Fishery-dependent communities

The original version of this article was revised: The article was originally published electronically on the publisher's internet portal (currently SpringerLink) without open access.

Jesse Coleman

jmcoleman2@alaska.edu

Courtney Carothers

clcarothers@alaska.edu

Rachel Donkersloot

rachel@akmarine.org

Danielle Ringer

djringer@alaska.edu

Paula Cullenberg

pcullenberg@alaska.edu

Alexandra Bateman

allie.bateman@noaa.gov
1 College of Fisheries and Ocean Sciences, University of Alaska Fairbanks, PO Box 757220, Fairbanks, AK 99775, USA

2 College of Fisheries and Ocean Sciences, University of Alaska Fairbanks, 1007 W. 3rd Avenue, Anchorage, AK 99501, USA

3 Alaska Marine Conservation Council, 106 F Street, Anchorage, AK 99501, USA

4 University of Alaska Fairbanks, Fairbanks, AK, USA

5 Alaska Sea Grant, 1007 W. 3rd Avenue, Anchorage, AK 99501, USA

6 National Oceanic and Atmospheric Administration, Alaska Fisheries Science Center, 301 Research Court, Kodiak, AK 99615, USA 


\section{Introduction}

The aging or "graying" of the commercial fishing fleet is an issue for the industry and fishery-dependent communities in coastal Alaska (Donkersloot and Carothers 2016). Between 1980 and 2016, the average age of a commercial fishery permit holder in Alaska has increased nearly 10 years (Gho and Farrington 2017). The increased average age of fishermen ${ }^{1}$ indicates that older fishermen are continuing to fish beyond their expected retirement age, and younger fishermen are not replacing them. This demographic shift has significant implications for the future of the industry and for the coastal economies of the state of Alaska, which are heavily dependent on seafood exports and tax revenues collected from the harvesting and processing sectors, as well as economic multiplier effects of people employed in the fishing industry.

Multiple barriers to entry in commercial fishing stemming from the privatization of fisheries access, including financial and other socioeconomic challenges, have made pursuing fishing careers significantly more difficult for young fishermen than in decades past (Donkersloot and Carothers 2016; Petterson 1983; Power et al. 2014; White 2015). The high capital costs, lack of access to capital in the form of loans, and lack of financial literacy and business management skills are a few of many financial barriers experienced by young people who desire a career in commercial fishing. The financial barriers to entry into the commercial fishing industry in Alaska are well-documented, but the outmigration of fishing rights and people, changing values in fishing, and social problems in fishing communities complicate such unidimensional economic explanations for the graying of the fleet trend (Carothers 2015; Ringer et al. in prep). For this reason, it is imperative that these issues be viewed through economic as well as social, cultural, and ecological lenses.

Barriers to entry are especially pertinent to the current generation of fishermen trying to make a successful livelihood from fishing, but uncertainty remains about the knock-on effects of graying trends on future generations of fishermen (and vice versa), namely today's youth living in coastal communities. For example, access rights and rights holders have migrated away from rural fishery-dependent communities over the past 40 years, restricting local access to fishing opportunities and weakening the social ties between fishing and the community (Carothers 2015; Langdon 1980; Knapp 2011; Gho and Farrington 2017; Donkersloot and Menzies 2015; Donkersloot 2010). These ties have been further threatened by commodity market instability and low fish prices, years of low fish abundance, and in some regions disasters like the Exxon-Valdez oil spill and threats like the development of large-scale mining projects (Braund 2017; Hébert 2015;

\footnotetext{
${ }^{1}$ We use the term "fishermen" for male and female fishery participants, as it is how they referred to themselves in this study.
}

Donkersloot 2007; Fall et al. 2006). Whether the remaining ties are strong enough to continue to engage youth in the industry on which coastal communities rely is as yet unclear.

Whether or not a young person decides to enter the commercial fishing industry is subject to influences beyond the people, places, and ideas out their front door. Today's American youth, known as Generation Z, are experiencing cultural shifts linked to technology, information, and social media, as well as changing parental expectations around higher education, work, and social mobility that have increasingly seen rural youth migrate away from resource-dependent communities (Corbett 2005; White 2015; Glendinning et al. 2003). For instance, while there is a wealth of literature on rural youth aspirations (e.g., Rérat 2014; Panelli 2002; Hamilton and Seyfrit 1993; Corbett 2013; Argent and Walmsley 2008), relatively little is understood about staying or leaving, going to college or going to work, and choosing a career path in the context of large-scale cultural shifts and the fishing industry in the USA.

The objective of this paper, as part of a larger study on graying of the fleet trends in Alaska (Donkersloot and Carothers 2016), is to examine the factors influencing young people's attitudes towards, and level of participation in, Alaskan fisheries. Are today's rural Alaska youth interested in pursuing fishing livelihoods? Or for that matter, do they expect to continue to live in rural Alaska? Based on our previous ethnographic research, we developed a survey to explore how the youngest generation of coastal residents perceives the fishing industry and their communities, by asking about their ties to fishing, their ambitions and desires for their own futures, and their feelings towards their communities. Quantitative and qualitative methods were used to draw inferences about students' attitudes about fishing and their communities and several geographic, social, and demographic factors derived from a school survey conducted among several study communities in the fishery-dependent regions of Bristol Bay and Kodiak Archipelago, Alaska.

\section{Methods}

\section{Study Site}

The Kodiak Archipelago, located in the west-central Gulf of Alaska of the North Pacific, is made up of Kodiak Island and several surrounding islands (Fig. 1). The region's largest community, Kodiak city, ${ }^{2}$ is home to a one of the most diverse, high-value (3rd in the USA; $\$ 137.5$ million in 2015), and high-volume (2nd in the USA; 513.9 million lbs. in 2015) commercial fishing ports in the USA (National Marine

\footnotetext{
${ }^{2}$ The community is named Kodiak, but will be hereafter referred to as Kodiak city to distinguish it from the larger Kodiak region.
} 
Fig. 1 Map of study areas and communities. Regional hub communities are represented by triangles $(\mathbf{\Delta})$ and village communities are represented by circles $(\bullet)$

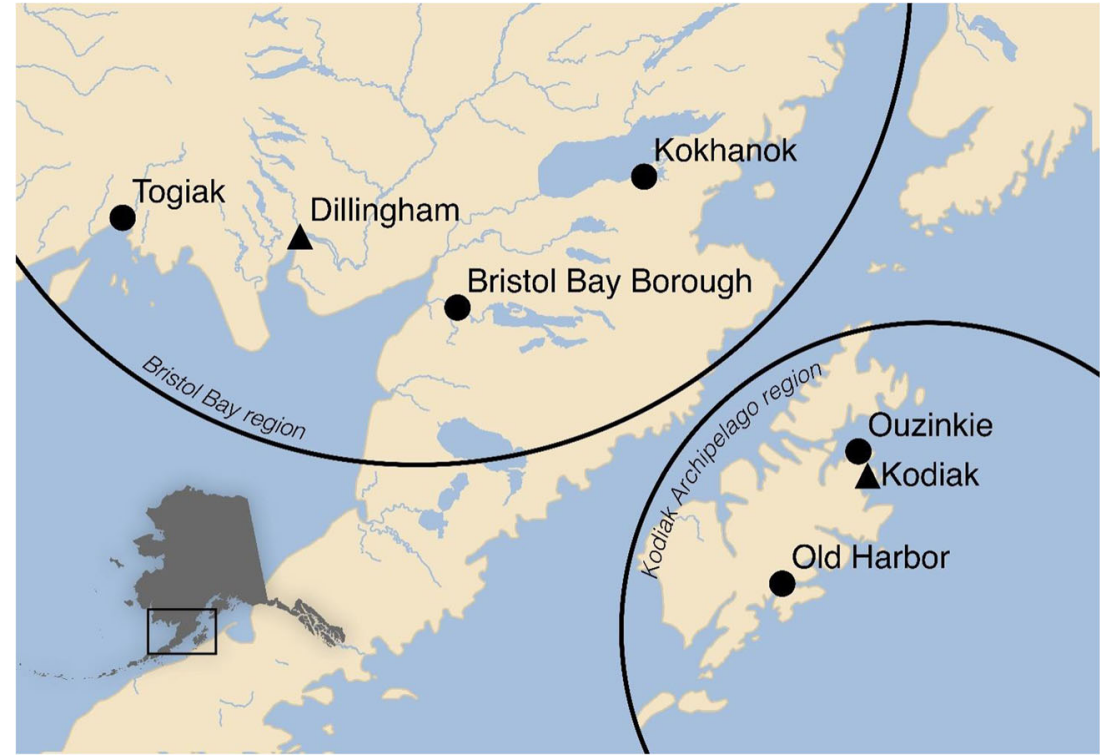

Fisheries Service 2017). The fisheries in the region target several species, including salmon, halibut, cod, and pollock among others, in geographically and temporally widespread fisheries. Fisheries are either state or federally managed, with varied access regimes and costs of entry and participation.

The Kodiak Archipelago communities selected for this study included Kodiak city, Ouzinkie, and Old Harbor. The Kodiak Island Borough, which includes communities within the Archipelago, had an estimated population of 13,732 in July 2016 (US Census Bureau 2017). In Kodiak city, which is the regional hub, nearly $14 \%$ of the population (6130) identifies as Alaska Native and 35\% identifies as Filipino - a population segment that has grown in part because of employment in the fish-processing sector (US Census Bureau 2016). Populations in communities off the Kodiak road system are 60 to $95 \%$ Alaska Native, and the dominant cultural group in these communities is Alutiiq/Sugpiaq (Alaska Native Heritage Center 2011; ADCCED 2017). The city of Kodiak is also home to the US Coast Guard Kodiak Air Station, which accounts for 1301 enlisted personnel and their family members living on the island (US Census Bureau 2017). Military families make up $17.5 \%$ of Kodiak city's residents. The village of Ouzinkie is located on Spruce Island, 12 miles north of Kodiak city accessible by air and water. Ouzinkie's population is 146, a majority of which are of Alutiiq/Sugpiaq and Russian ancestry. Old Harbor, a village of 214 people, lies about 40 air miles south of Kodiak city. The communities' residents are also of Alutiiq/Sugpiaq and Russian descent, and subsistence harvests of fish, game, and wild plants are the cornerstone of life in both Old Harbor and Ouzinkie.

The Bristol Bay region is located in southwestern Alaska on the eastern edge of the Bering Sea. Its commercial fisheries are eighth in value (\$90.1 million in 2015), and 18th in volume (69.6 million lbs. in 2015). The Bay is home to the largest wild sockeye salmon fishery in the world. A vast majority of fishing effort and harvest in the region is directed to the statemanaged sockeye salmon fishery, although Chinook and Coho salmon are also harvested commercially to a lesser extent. Other fisheries include federal individual fishing quota (IFQ) halibut and state limited entry herring sac roe in the Togiak district of the Bay. The region includes multiple census-designated places, the Bristol Bay Borough, the Lake and Peninsula Borough, and the Dillingham census area (unorganized borough). Roughly half of the Bristol Bay region's 6848 residents identify as Alaska Native, though hub communities tend to have relatively fewer Alaska Native residents than villages (ADCCED 2017).

The four Bristol Bay communities selected for this study include Togiak, Dillingham, Kokhanok, and the Bristol Bay Borough (which includes Naknek, South Naknek, and King Salmon). The western Bristol Bay hub community of Dillingham is home to 2300 year-round residents, $59 \%$ of whom identify as Alaska Native. A majority of Indigenous people in coastal areas of Bristol Bay are Yup'ik, which is a branch of the larger circumpolar Inuit cultural group. Located in Dillingham are most of the region's government services and a regional hospital. The village of Togiak is located approximately 40 air miles west of Dillingham, and has a population of 870 ( $80 \%$ are Yup'ik). Many residents participate in the super-exclusive commercial salmon fishery in Togiak Bay (i.e., if a permit holder registers in Togiak Bay, they may not fish in another district). Kokhanok is a village of 173 people located on the southwestern shore of Lake Iliamna, roughly 90 miles as the crow flies from the marine coast of Bristol Bay. Eighty percent of Kokhanok's residents are Alaska Native, and identify as Dena'ina Athabascan or Yup'ik. The three communities of the Bristol Bay Borough lie close in proximity, and government services and private businesses are spread 
amongst the communities and along the 15-mile-long road system. The communities of Naknek (population 504), South Naknek (74), and King Salmon (309) are the east side home to the bay's commercial fish processing activity, with over a dozen shorebased processing facilities and a busy airport. All study communities rely on subsistence hunting, fishing, and gathering to fulfill nutritional, spiritual, and sociocultural needs.

\section{Target and Sampling Frame}

Our target frame consisted of seventh through 12th grade students in public schools in the study communities. Communities were selected because the investigators had previously established research relationships with them, and the set of chosen study communities represented different attributes (e.g., participation in fisheries access programs, population, remoteness; see Donkersloot and Carothers 2016). Additionally, previous phases of this project involved ethnographic interviews with fishery participants and leaders in the study communities (see Ringer et al. in review). Because the communities were not selected randomly, our goal with the survey and subsequent analyses was to make general inferences about youth fishing and community attitudes in the study communities and regions, and not to extend these inferences to communities that were not surveyed. The sampling frame included all students who attended classes the day the survey was administered, whose parents consented to allowing their child to take anonymous surveys during the 2014-2015 school year, and who volunteered to take the survey. In the Kodiak Archipelago region (Kodiak Island Borough School District, KIBSD), the schools surveyed included Kodiak Middle/High School, Ouzinkie School, and Old Harbor School. In Bristol Bay, Kokhanok School (Lake and Peninsula School District), Togiak School (Southwest Regional School District), Dillingham Middle/High School (Dillingham School District), and the Bristol Bay Borough School (BBB School District) were surveyed.

\section{Survey Instrument and Implementation}

A survey was developed from key concepts relating to youth and the fishing industry that emerged from interviews with community leaders and fishermen in the study communities. The five-page printed survey included three sections: (1) fishing background and student opinions, (2) community, and (3) student demographic information. The estimated length of time to complete was $20 \mathrm{~min}$ to $1 \mathrm{~h}$. In Bristol Bay, parental assent forms were sent home with students 1 to 3 days prior to implementation of the survey, asking them to sign and return the form if they did not want their child to participate. In the Kodiak Island Borough School District, parents were given a form at the beginning of the school year to obtain consent for their child to participate in surveys that did not collect sensitive information (e.g., names, birth dates, social security numbers). The authors administered the surveys with the support and approval of school staff, except in Kokhanok, where a local assistant was hired to distribute and collect surveys. Generally, surveys were distributed to teachers, students completed surveys anonymously during a single class period, and surveys were returned to researchers or the local assistant by the end of the school day. Raffles for gift cards to local stores were held at each school to thank students for survey completion.

\section{Data Preparation}

Survey responses were entered, coded, and stored in a Microsoft Excel spreadsheet. A subset of variables was selected for inclusion in regression analyses based on descriptive statistics and survey items specifically included to address research objectives. To account for item non-response (i.e., where students left one or several answers blank), missing value imputation was conducted using the mice function and package in R statistical software, using polytomous regression for categorical variables and predictive mean matching for continuous variables (R Core Team 2017; van Buuren and Groothuis-Oudshoorn 2011).

\section{Likert Scale Construction}

Two scales were constructed for the regression analyses: one based on a series of Likert items that asked students about their perceptions of the fishing industry, and another on Likert items pertaining to perceptions of their communities. Likert items were analyzed so that they measured positive perceptions of fishing and community; negatively phrased items were reverse coded. Hereafter, the scales will be referred to as "fishing attitude" and "community attitude."

A subset of Likert items was selected for scale construction using a graded response model, employing the grm function in R package ltm (Rizopoulos 2006). This function seeks to identify a single underlying trait from a series of multiple choice questions, and allows the researcher to select only those questions whose responses provide useful information about the latent trait-in this case, "positive fishing attitude" or "positive community attitude." This approach uses parametric, maximum-likelihood estimation in assessing scale reliability, rather than using a single metric like Cronbach's $\alpha$. Cronbach's $\alpha$ assumes that the items within a scale are sampled at random from a domain of relevant items and reliability is calculated by reconfiguring variances into informative metrics (Cortina 1993; Tavakol and Dennick 2011). Item response theory and grm treats items as "random replicates of each other, and their characteristics, if examined at all, are expressed as correlations with total test score or as factor loadings on the putative latent variable(s) of interest" (Revelle 2007). Likert 
items were selected for inclusion in the respective Likert scales if the corresponding item information curves provided information as to the respondent's level of the underlying latent trait (i.e., positive fishing or community attitude).

Finally, fishing attitude and community attitude scales were adjusted and rescaled to fit the following interpretation: a fishing or community attitude score of zero indicated that the student responded "Strongly Disagree" to all Likert items that comprised the scale, and a score of 1 indicated all "Strongly Agree" responses. These scales were then modeled as response variables in a univariate linear regression modeling framework using function svyglm in package survey, which is specifically designed for modeling complex survey data (Lumley 2011).

\section{Regression Modeling}

To ensure robustness of the response variable to linear modeling methods, the scales were modeled first as linear, then as logistic responses, the latter because parameter values that are bounded by zero and one are generally difficult to estimate using linear regression. The resulting parameter estimates and standard errors were very similar between the models (less than $1 \%$ difference in estimates), so linear responses were used because their parameter estimates are simpler and more intuitive to interpret than logistic regression parameter estimates. A range of models was developed as a candidate model set to be evaluated in a multimodel inference framework (Burnham and Anderson 2002). A saturated model, all leave-one-out models (i.e., one predictor variable was left out of the model in succession), and models consisting of subsets of predictors corresponding to geographic, demographic, and sociocultural factors were included in candidate model sets for fishing attitude and community attitude analyses, respectively.

The dAIC criterion, a version of Akaike's information criterion modified for survey data, was used to compare model likelihoods among candidate models (Lumley 2011). The dAIC is a relative measure that expresses the weight of evidence in favor of any model in the set being the "true" model from which the data were sampled. A difference of dAIC between any model and the lowest-ranked model is the delta dAIC, and a delta dAIC of seven is interpreted as virtually no support in the data for the model in question being the "true" model. All candidate models with delta dAIC less than seven were included in the plausible model set, across which parameter estimates were averaged.

\section{Regression Trees/Random Forests}

Conditional inference trees recursively split a dataset according to categories or threshold values of the predictors most strongly associated with the response variable. Splits are made in the dataset until the null hypothesis of "no association between predictor $x$ and the response" can no longer be rejected. The building of the conditional inference trees for the fishing and community attitude scales gave an indication of which variables were most important in identifying potential groups of respondents. Linear regression analysis gives estimates of the numerical relationships between each predictor and the response variable independently (unless interaction effects are specified), while regression trees are a non-parametric way to understand the importance of each predictor variable in relation to the others. Conditional inference trees for fishing attitude and community attitude scales were constructed using the $\mathrm{R}$ function ctree in package partykit. Random forests are groups of regression trees, each formed from a random, withreplacement sample of the training dataset. Random forests for fishing and community attitude scales were used to minimize the uncertainty in node placement that characterizes single regression trees. The random forests were constructed using the package randomForest in $\mathrm{R}$.

Table 1 Response rates by community; number of surveys completed by 7 th-12th grade students (three 6th graders took the survey) divided by the number of students enrolled in middle and high schools in each community during the 2014-2015 school year

\begin{tabular}{|c|c|c|c|c|c|}
\hline Region & Community name & Enrollment & Surveys completed & Opted out & Response rate \\
\hline \multirow[t]{5}{*}{ Bristol Bay } & Bristol Bay Borough & 59 & 51 & 0 & $86 \%$ \\
\hline & Dillingham & 211 & 128 & 0 & $61 \%$ \\
\hline & Kokhanok & 7 & 5 & 0 & $71 \%$ \\
\hline & Togiak & 86 & 20 & 4 & $23 \%$ \\
\hline & Region total & 363 & 204 & 4 & $56 \%$ \\
\hline \multirow[t]{4}{*}{ Kodiak Archipelago } & Kodiak city & 1050 & 579 & 0 & $55 \%$ \\
\hline & Old Harbor & 24 & 13 & 0 & $54 \%$ \\
\hline & Ouzinkie & 30 & 15 & 0 & $50 \%$ \\
\hline & Region total & 1104 & 607 & 0 & $56 \%$ \\
\hline Grand total & & 1467 & 811 & 4 & $55 \%$ \\
\hline
\end{tabular}


Fig. 2 Student ethnicity by study region for Kodiak Archipelago (light bars) and Bristol Bay (dark bars) students. Students were instructed to check all that applied, so totals may sum to more than $100 \%$ of respondents for some categories

\section{Results}

\section{Summary Statistics}

Over 800 surveys were completed for this study. Survey response rates, defined as the number of students that completed the survey divided by the State of Alaska official enrollment for each school, are listed in Table 1. The ethnic identities of students differed markedly between Kodiak Archipelago and the Bristol Bay regions, with most students identifying as Alaska Native in Bristol Bay $(78 \% ; n=148)$ and as white in Kodiak Archipelago (40\%; $n=213$; Fig. 2), although $100 \%$ identified as

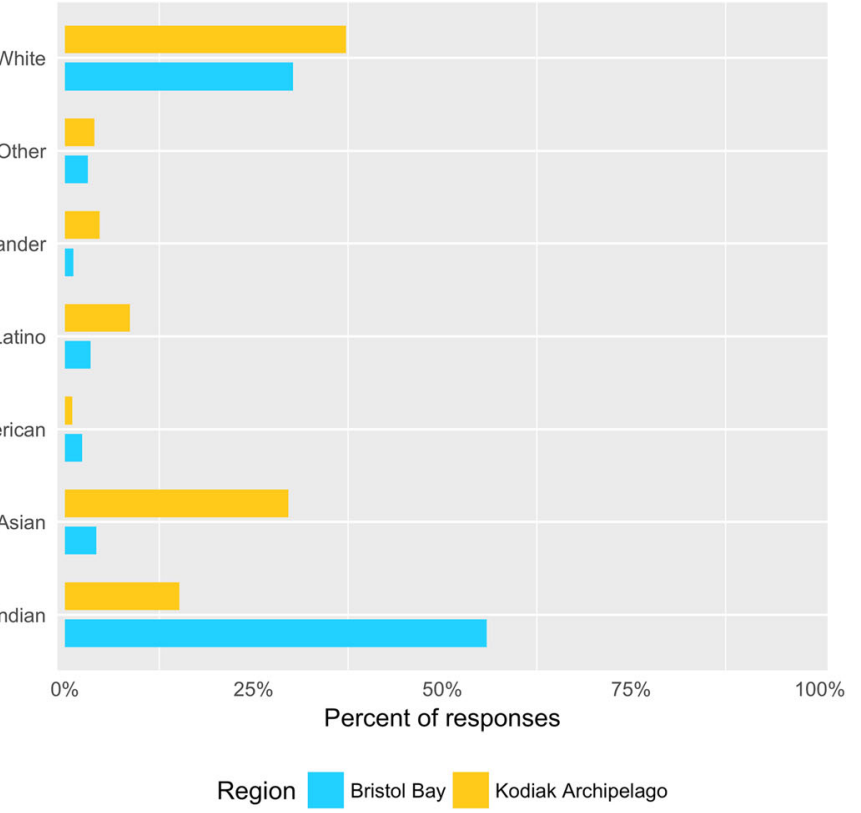

Alaska Native in the Kodiak villages of Old Harbor and Ouzinkie. Preliminary analyses revealed contrasts in the kinds and strength of student ties to fishing between communities, principally that fewer than $9 \%$ of Kodiak city students $(n=48)$ had fished commercially at some point in their lives (Fig. 3). In the Bristol Bay hub community of Dillingham, this figure was $45 \%(n=57)$. Roughly 60 $80 \%$ of all Bristol Bay, Ouzinkie, and Old Harbor students reported levels of current and past family engagement in fishing, while $22 \%(n=112)$ and $31 \%(n=143)$ of students reported current and past family ties, respectively, in Kodiak city (Fig. 3). Responses to selected fishing attitude Likert items are presented in Figs. 4 and 5.
Fig. 3 Ties to fishing by community for students in the Kodiak Archipelago (top panel) and Bristol Bay (bottom panel) regions

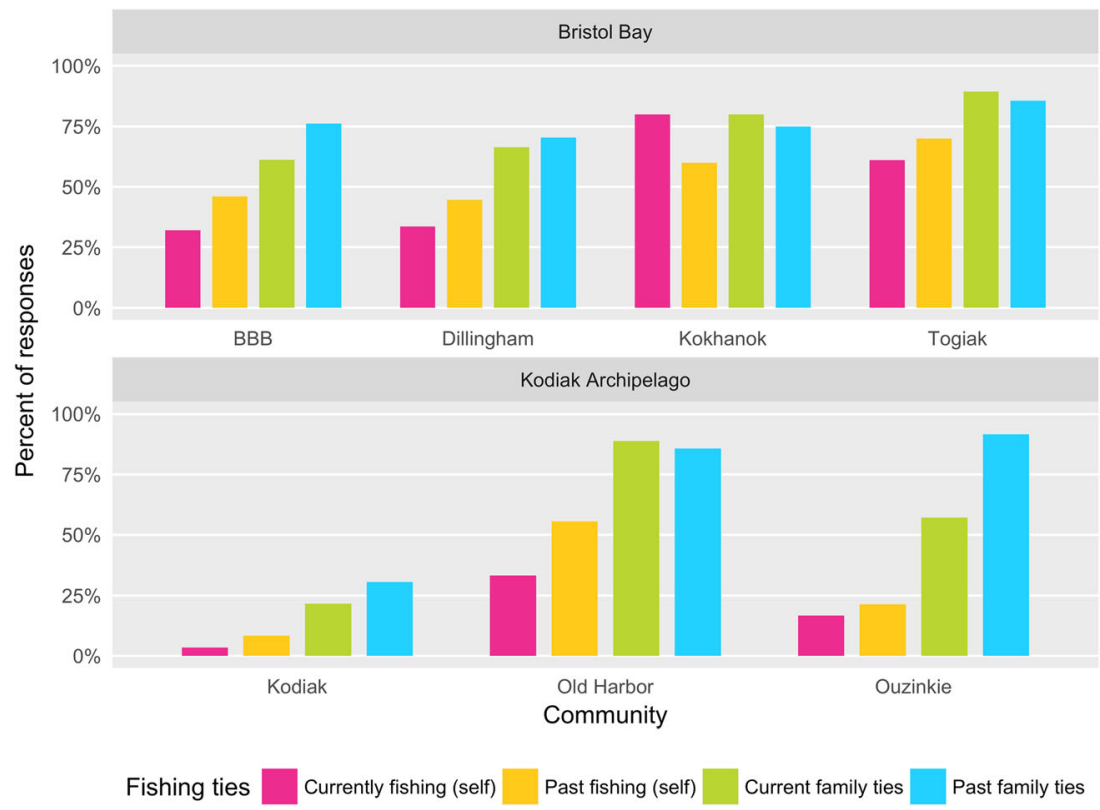


Fig. 4 Bristol Bay region responses by community for a selection of Likert items related to fishing attitudes

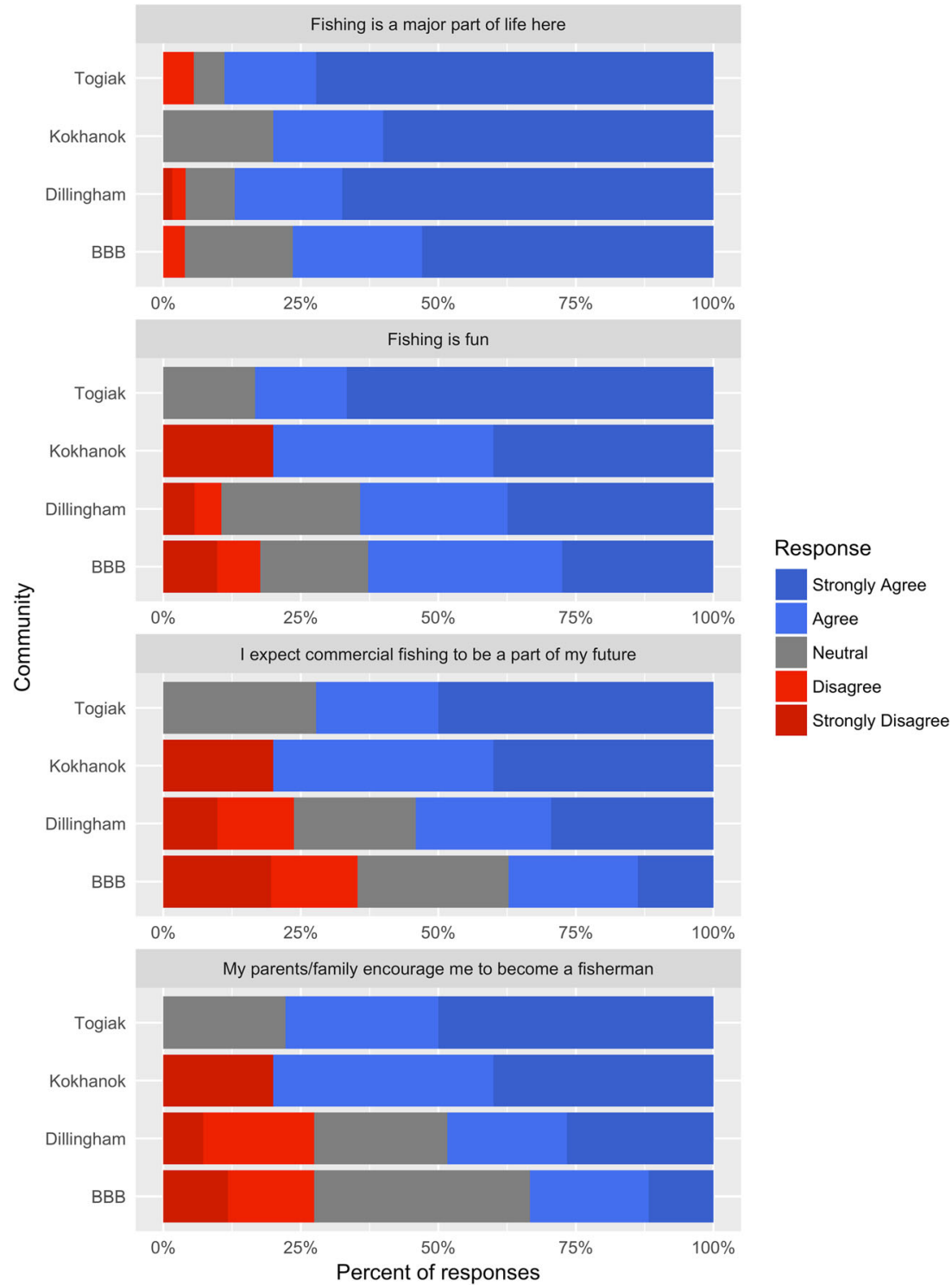

Overall, there was strong agreement that youth enjoy living in their communities now $(63 \%, n=495)$, but $23 \%$ of respondents $(n=180)$ disagreed with the statement "the future looks good for people who stay" (Figs. 6 and 7). Similarly, about one in five students wanted to leave their communities and not return, and two in five were not sure of their plans. Put differently, $38 \%$ of respondents $(n=300)$ hoped to return to their communities at some point in the future, whether permanently or seasonally. Responses to questions about particular aspects of community and the student's life there encompassed many factors, some of which were related to social well-being within the community. According to answers to open-ended questions, youth plainly recognized the challenges faced by their communities, and the most commonly cited concern was drug and alcohol abuse $(44 \% ; n=279)$. Students also identified concerns such as remoteness and high costs of living (4\%; $n=35)$, crime and violence $(5 \% ; n=28)$, and the limited and shrinking availability of local jobs $(3 \% ; n=22)$. Roughly $10 \%$ of respondents had no concerns about their community.

\section{Regression Results}

A two-sample $t$ test revealed significant differences in fishing attitude between regions ${ }^{3}\left(\hat{\bar{x}}_{B B}=0.65, \hat{\bar{x}}_{K A}=0.41\right.$; $\left.p<2.2 \times 10^{-16}\right)$, but not community attitude $\left(\hat{\bar{x}}_{B B}=0.58\right.$, $\left.\hat{\bar{x}}_{K A}=0.60 ; p=0.43\right)$. However, neither the regression nor conditional inference tree results suggest that region is a strong predictor of fishing or community attitude scores. The regression parameters can be interpreted as the percent change in the fishing or community attitude score resulting from a one-unit increase (or going from the baseline to the category

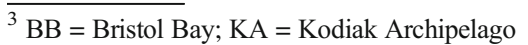


Fig. 5 Kodiak Archipelago region responses by community for a selection of Likert items related to fishing attitudes

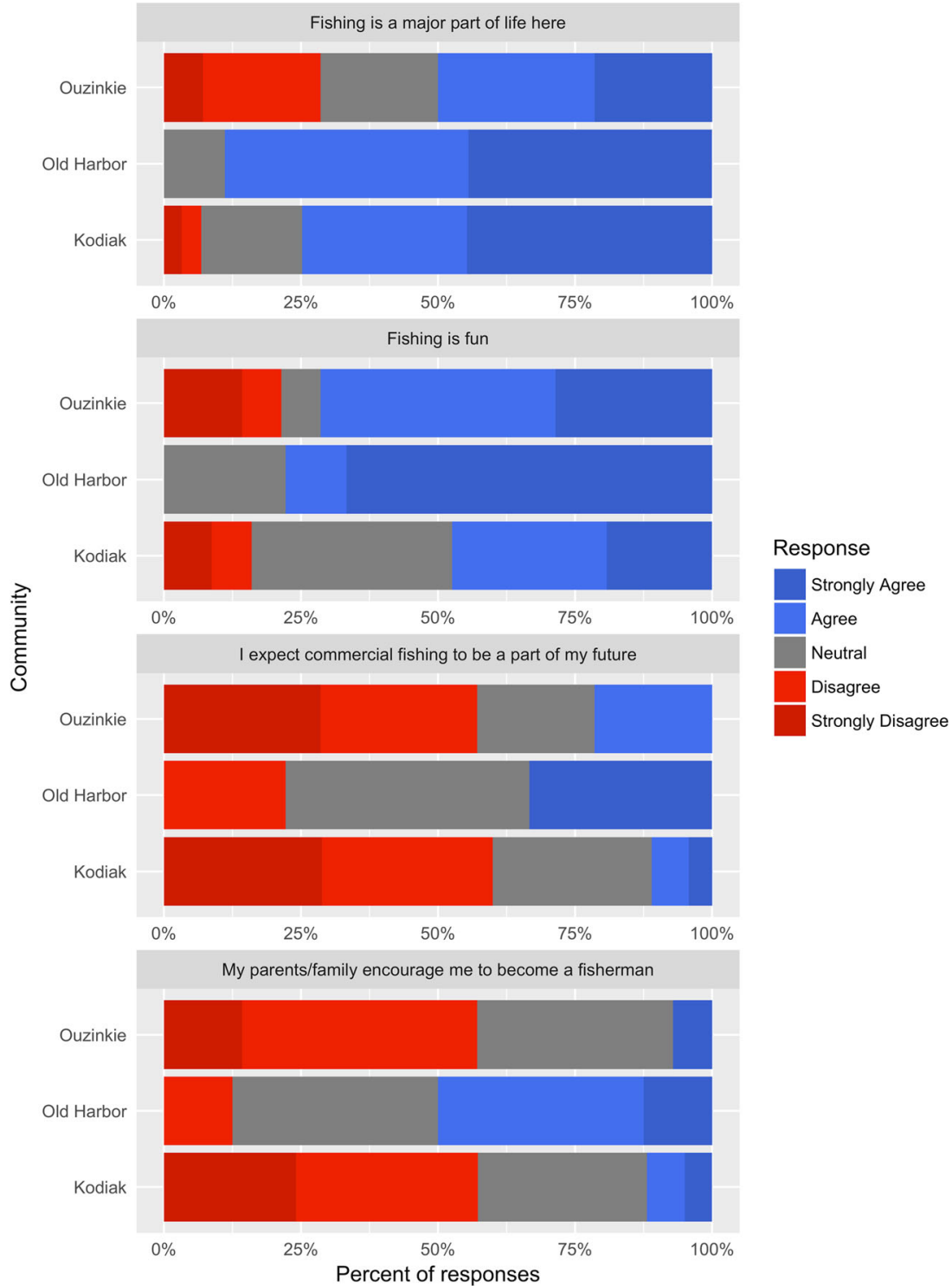

in question) in the predictor variable. For instance, for a 1-year increase in age, a student's fishing attitude score would be expected to decrease by $0.3 \%$. For a categorical predictor, the interpretation changes slightly. For example, for students in the Region category Bristol Bay (i.e., they are from a community in the Bristol Bay study region), an increase of $2.6 \%$ in fishing attitude is expected relative to students the baseline category, which is the Kodiak Archipelago (Table 2).

The important predictors of fishing attitude (Table 2) included student experience in the commercial fishing industry, whether the student wanted to be involved in fishing in the future, and the importance of subsistence fishing to the student's family. Not having fishing experience decreased the student's estimated score by roughly $10 \%$ compared to those with fishing experience, while not wanting to be involved in fishing in the future decreased fishing attitude by $20 \%$ relative to those who did want to be involved in the future. Students who said subsistence fishing "used to be important," was "somewhat important," or "very important" had fishing attitude scores roughly $2.7 \%, 5 \%$, and $11 \%$ higher, respectively, than those who said subsistence fishing was not important to their family. Similarly, students who rated the importance of income from commercial fishing as "somewhat important" or "very important" to their family had $3.4 \%$ and $7 \%$ higher scores, respectively, than those who rated family fishing income as "not important." Family fishing history also had positive effects on fishing attitude score. Students who reported their family having fished in the past, fished in the past and present, and presently fishing but not in the past, showed increases in scores of $4.9 \%, 7 \%$, and $3.6 \%$, respectively, compared to students whose families have never fished. Demographic variables such as age, gender, Alaska Native heritage, and whether or not students grew up in the communities in which they were surveyed all had minimal effects on fishing attitude score. 
Fig. 6 Bristol Bay region responses by community for a selection of Likert items related to community attitudes

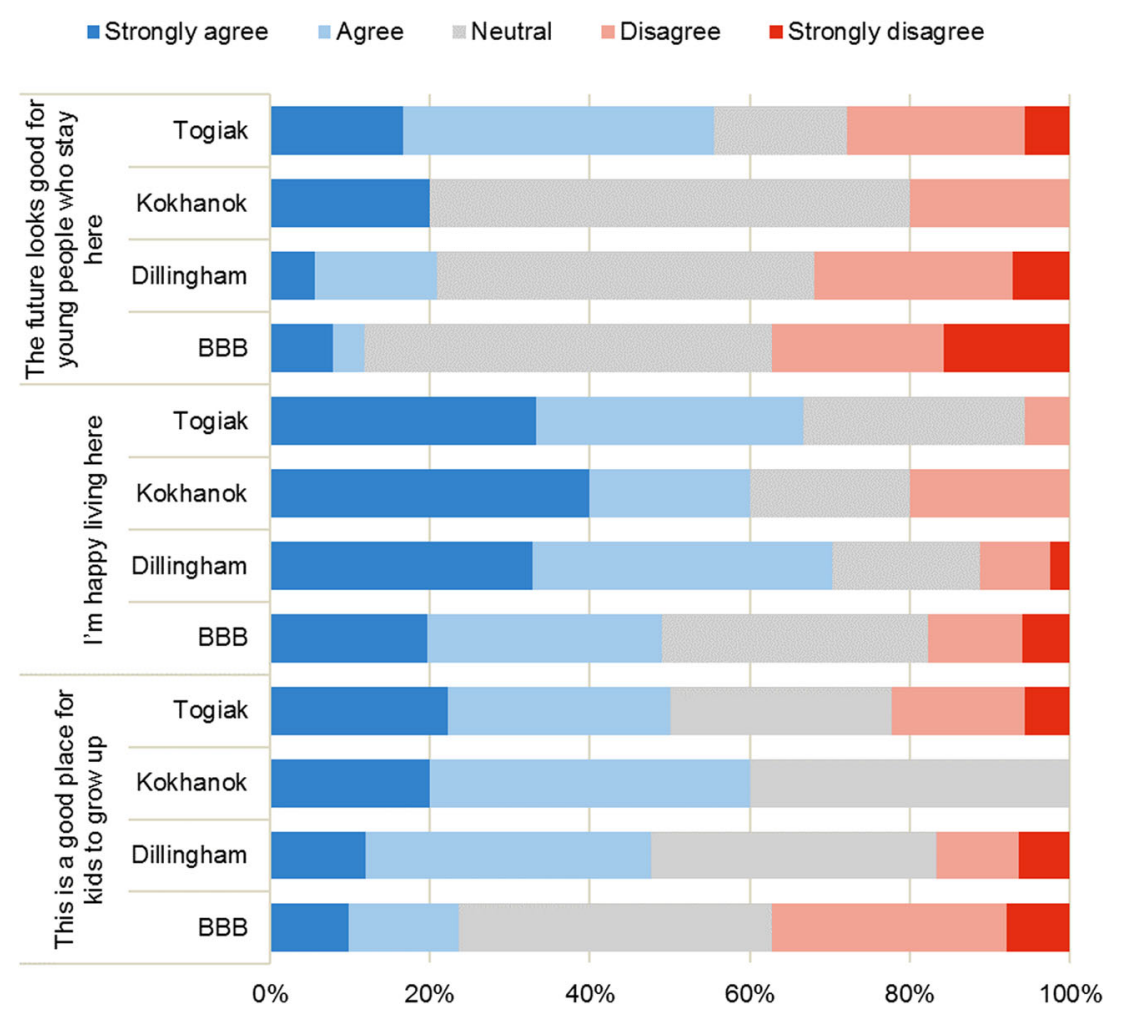

Important predictors of community attitude were age, how the student felt about their life, the importance of subsistence activity to their family, and whether the student grew up in the community in which they were surveyed (Table 3 ). Community attitude score decreased about $1 \%$ for each year of increasing age, or put differently, older students had slightly less positive community attitudes than younger students. A negative "outsider" effect was observed, in that students who did not grow up in the community had scores on average $8 \%$ lower than those who did. In Kodiak city in particular, a substantial portion of the student body came from military families that migrated to Kodiak from other US cities, although we did not specifically ask about family military engagement. An increase in community attitude score of about $8 \%$ was estimated for those who responded "life is good" versus those who said "life is bad." Students who said subsistence is "somewhat" or "very important" had community attitude scores $5.8 \%$ and $11 \%$ greater, respectively, than those who said subsistence was "not at all" important to their families. Complex models were favored in the model selection process, and all but the null model and those including subsets of demographic variables and a region by hub/village interaction were included in the plausible model set $(\mathrm{dAIC}<4)$.

\section{Regression Trees/Random Forest Results}

The top three most important predictors of positive fishing attitude were student's fishing experience, their desire to fish commercially in the future, and their family ties to fishing
(Table 4). The importance of income from commercial fishing and subsistence fishing activity to a student's family were also important predictors of positive fishing attitude. With respect to community attitude (Table 5), the top three most important predictors of positive community attitude were the student's age, how they feel about their life, and the importance of subsistence fishing activity to their family. Whether the student grew up in the community was also an important predictor of community attitude (see discussion below). The results of the random forest generally agree with those of the dAICaveraged generalized linear models.

\section{Discussion}

The factors associated with holding a positive view of commercial fishing among youth in this study included student experience in commercial fishing, family ties to commercial fishing, the importance of commercial fishing income, and subsistence fishing to the student's family. Taken together, these results suggest that the more numerous a young person's ties to fishing, and the greater their level of exposure to fishing, and thus the more positively they regard commercial fishing. With respect to community, factors associated with positive perceptions included age, student well-being, importance of subsistence fishing to family, and whether a student was raised in the community. Below, we discuss these factors in the context of previous research on youth attitudes about fishing, linkages between subsistence and commercial fishing 
Fig. 7 Kodiak Archipelago region responses by community for a selection of Likert items related to community attitudes

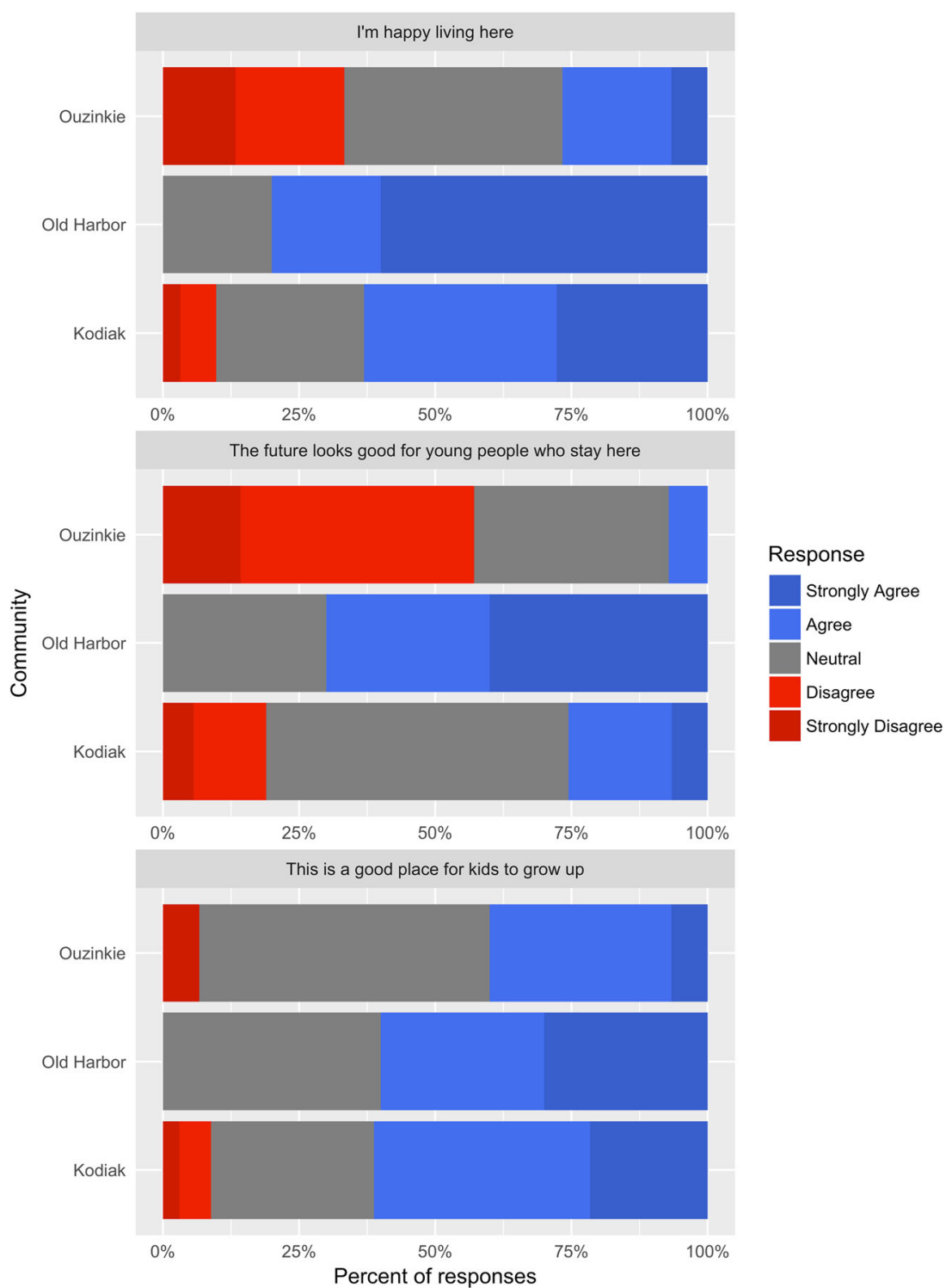

practices, and the enduring effects on youth fishery engagement of privatization of access in Alaska's coastal communities (Figs. 8 and 9).

\section{Fishing Attitude}

Exposure to, engagement in, and family ties to commercial and subsistence fishing are important predictors of positive fishing attitude, and they are critical for sustaining new entry into fishing livelihoods. Youth in coastal communities are often first exposed to fishing through subsistence practices, or the gathering of wild foods for family and community use and sharing. Subsistence is a way of life for many rural Alaska residents, and studies among rural Arctic communities support the existence of a financial link between income from commercial fishing and the ability to purchase fuel and equipment for subsistence (e.g., Holen 2009, 2014; Poppel 2006; Reedy-
Maschner 2009). Here, we have clearly demonstrated a positive relationship between engagement in subsistence activities and youth attitudes about commercial fishing. Subsistence fishing at setnet sites was often described by Bristol Bay interview participants as a "training ground" of sorts, where children too young to be on commercial drift vessels or fastpaced setnet sites were exposed to fishing, learned some of the necessary skills to be successful fishermen, and formed their identity around fishing. Holen's (2009) study in Kokhanok and other rural Alaska communities describes the transmission of cultural knowledge and traditional values to youth through family fishing experiences, and the importance of both types of fishing to the well-being of the community. Not only does commercial fishing enable subsistence fishing financially, but the two may be mutually reinforcing by fostering interest in the practice of fishing among the community's youth. 
Table 2 Positive view of fishing model-averaged parameter estimates (95\% confidence level). Parameter estimates were averaged according to methods by Burnham and Anderson (2002), modified for design-based survey data using methods by Lumley and Scott (2015)

\begin{tabular}{|c|c|c|c|c|c|c|c|}
\hline Parameter & Baseline & Category & $\begin{array}{l}\text { Mod. avg. } \beta \\
\left.\widetilde{\widetilde{\beta}}_{j}\right)\end{array}$ & $\begin{array}{l}\text { Variance } \\
\text { (unconditional) }\end{array}$ & $\begin{array}{l}\text { SE } \\
\text { (unconditional) }\end{array}$ & $\begin{array}{l}\text { Lower } \\
\text { bound }\end{array}$ & $\begin{array}{l}\text { Upper } \\
\text { bound }\end{array}$ \\
\hline (Intercept) & - & - & 0.6133 & 0.2945 & $8.67 \times 10^{-2}$ & 0.4433 & 0.7832 \\
\hline Region & $\begin{array}{l}\text { Kodiak } \\
\text { Archipelago }\end{array}$ & Bristol Bay & 0.0257 & 0.0005 & $2.50 \times 10^{-7}$ & 0.0257 & 0.0257 \\
\hline Hub/village & Village & Hub & -0.0044 & 0.0012 & $1.39 \times 10^{-6}$ & -0.0044 & -0.0044 \\
\hline Fishing experience & Yes & No & -0.1047 & 0.0152 & $2.32 \times 10^{-4}$ & -0.1051 & -0.1042 \\
\hline Desire to fish in the future & Yes & No & -0.2034 & 0.0466 & $2.17 \times 10^{-3}$ & -0.2077 & -0.1992 \\
\hline \multirow[t]{3}{*}{ Family fishing } & \multirow[t]{3}{*}{ Never } & Past only & 0.0494 & 0.0012 & $1.55 \times 10^{-6}$ & 0.0494 & 0.0494 \\
\hline & & $\begin{array}{l}\text { Past and } \\
\text { present }\end{array}$ & 0.0700 & 0.0028 & $7.90 \times 10^{-6}$ & 0.0700 & 0.0700 \\
\hline & & Present only & 0.0359 & 0.0008 & $7.17 \times 10^{-7}$ & 0.0359 & 0.0359 \\
\hline \multirow[t]{3}{*}{ Income importance } & \multirow[t]{3}{*}{ Not at all } & Used to be & 0.0008 & 0.0009 & $8.68 \times 10^{-7}$ & 0.0008 & 0.0008 \\
\hline & & Somewhat & 0.0340 & 0.0006 & $3.53 \times 10^{-7}$ & 0.0340 & 0.0340 \\
\hline & & Very & 0.0684 & 0.0025 & $6.35 \times 10^{-6}$ & 0.0684 & 0.0684 \\
\hline \multirow[t]{3}{*}{ Subsistence importance } & \multirow[t]{3}{*}{ Not at all } & Used to be & 0.0277 & 0.0008 & $5.85 \times 10^{-7}$ & 0.0277 & 0.0277 \\
\hline & & Somewhat & 0.0507 & 0.0014 & $2.03 \times 10^{-6}$ & 0.0507 & 0.0507 \\
\hline & & Very & 0.1080 & 0.0078 & $6.11 \times 10^{-5}$ & 0.1079 & 0.1081 \\
\hline Desire to go to college & Yes & No & 0.0063 & 0.0008 & $7.17 \times 10^{-7}$ & 0.0063 & 0.0063 \\
\hline $\begin{array}{l}\text { Student grew up in } \\
\text { community }\end{array}$ & Yes & No & 0.0039 & 0.0002 & $4.80 \times 10^{-8}$ & 0.0039 & 0.0039 \\
\hline Age & - & - & -0.0028 & 0.0000 & $1.70 \times 10^{-9}$ & -0.0028 & -0.0028 \\
\hline Gender & Female & Male & 0.0288 & 0.0005 & $2.08 \times 10^{-7}$ & 0.0288 & 0.0288 \\
\hline Alaska Native identity & No & Yes & 0.0172 & 0.0003 & $8.97 \times 10^{-8}$ & 0.0172 & 0.0172 \\
\hline Region/hub interaction & & & -0.0019 & 0.0001 & $3.58 \times 10^{-9}$ & -0.0019 & -0.0019 \\
\hline
\end{tabular}

Enduring family ties to fishing provides knowledge, skills, and financial capital that facilitate youth engagement in commercial fishing. In this study, youth who possessed multigenerational family ties to fishing had $7 \%$ higher fishing attitude scores than those who had neither past nor current family members fishing. Family ties are a critical feature of how youth perceive the opportunities available to them (Glendinning et al. 2003), and they have changed dramatically

Table 3 Positive view of community model-averaged parameter estimates, standard errors, and 95\% confidence intervals. Parameter estimates were averaged according to methods by Burnham and Anderson (2002), modified for design-based survey data using methods by Lumley and Scott (2015)

\begin{tabular}{|c|c|c|c|c|c|c|}
\hline Parameter & Baseline & Category & Mod. avg. $\beta\left(\overline{\bar{\beta}}_{\boldsymbol{j}}\right)$ & SE (unconditional) & Lower bound & Upper bound \\
\hline (Intercept) & - & - & 0.5890 & $3.55 \times 10^{-2}$ & 0.5195 & 0.6585 \\
\hline Region & Kodiak Archipelago & Bristol Bay & -0.0580 & $1.76 \times 10^{-4}$ & -0.0584 & -0.0577 \\
\hline Hub/village & Village & Hub & 0.0128 & $1.08 \times 10^{-4}$ & 0.0125 & 0.0130 \\
\hline Fishing experience & Yes & No & -0.0113 & $3.96 \times 10^{-5}$ & -0.0114 & -0.0112 \\
\hline \multirow[t]{3}{*}{ Subsistence importance } & \multirow[t]{3}{*}{ Not at all } & Used to be & 0.0342 & $1.77 \times 10^{-4}$ & 0.0338 & 0.0345 \\
\hline & & Somewhat & 0.0583 & $3.71 \times 10^{-5}$ & 0.0583 & 0.0584 \\
\hline & & Very & 0.1184 & $2.19 \times 10^{-4}$ & 0.1180 & 0.1188 \\
\hline Student grew up in community & Yes & No & -0.0824 & $9.18 \times 10^{-5}$ & -0.0826 & -0.0822 \\
\hline Age & - & - & -0.0123 & $1.85 \times 10^{-7}$ & -0.0123 & -0.0123 \\
\hline Gender & Female & Male & 0.0173 & $1.11 \times 10^{-5}$ & 0.0173 & 0.0173 \\
\hline Alaska Native identity & No & Yes & -0.0084 & $1.81 \times 10^{-5}$ & -0.0084 & -0.0083 \\
\hline \multirow[t]{2}{*}{ How student feels about life } & \multirow[t]{2}{*}{$\mathrm{Bad}$} & Not sure & -0.0012 & $2.81 \times 10^{-7}$ & -0.0012 & -0.0012 \\
\hline & & Good & 0.0803 & $3.18 \times 10^{-3}$ & 0.0741 & 0.0866 \\
\hline Region/hub interaction & & & 0.1809 & $5.59 \times 10^{-3}$ & 0.1699 & 0.1918 \\
\hline
\end{tabular}


Table 4 Variable importance measures from random forest of fishing attitude scale. Importance rank based on the mean decrease in mean squared error (MSE) among response values achieved by inclusion of the predictor variable in question in the random forest model

\begin{tabular}{llcc}
\hline Predictor variable & Increase in MSE (\%) & Increase in node purity & Importance rank \\
\hline Region & 0.0015 & 1.28 & 8 \\
Hub/village & 0.0007 & 0.77 & 11 \\
Fishing experience & 0.0054 & 5.31 & 2 \\
Desire to fish in the future & 0.0189 & 11.05 & 1 \\
Family fishing & 0.0053 & 4.49 & 3 \\
Income importance & 0.0053 & 4.31 & 4 \\
Subsistence importance & 0.0043 & 4.29 & 5 \\
Desire to go to college & 0.0001 & 0.66 & 12 \\
Student grew up in community & 0.0002 & 0.84 & 10 \\
Age & 0.0001 & 3.30 & 6 \\
Gender & 0.0009 & 1.20 & 9 \\
Alaska Native identity & 0.0021 & 1.40 & 7 \\
\hline
\end{tabular}

since the privatization of access in many Alaskan fisheries in the mid-1970s (state limited entry program) and again in the mid-1990s (federal IFQ program). As families sold fishing rights during the initial period of privatization or moved away from their communities, an important opportunity to expose future generations of their family to fishing was lost, in many cases permanently (Apgar-Kurtz 2015; Langdon 1980; Reedy-Maschner 2007; Carothers 2008). In other cases, families were never engaged in fishing. For example, $20.6 \%$ of respondents in Kodiak city immigrated to fishing communities from the lower 48 states (e.g., US Coast Guard families) or outside the USA (e.g., Filipino families working in seafood processing sector), and likely do not have the same social or familial attachments and exposure to commercial fishing that youth with long family histories in the community and region have, and may not participate in fishing to the same extent. This feature of the social structure of Kodiak city, as compared to other Kodiak Archipelago villages and to hub and village communities in the Bristol Bay region, partially explains why youth have proportionally lower levels of engagement in fisheries. However, as is the case for most fishery-dependent communities in Alaska, Kodiak city has also experienced the loss of locally held fishing rights that accompanies privatized access regimes (Carothers 2015; Himes-Cornell and Hoelting 2015).

A student's desire to fish in the future is a strong positive predictor of fishing attitude (and vice versa). These relationships reinforce the notion that engagement in commercial fishing at a young age breeds interest in the practice later on. Youth attitudes towards fishing, among other things, are also heavily influenced by interactions with and the expectations of families and their peers (Byun et al. 2012; White 2015). In the interview phase of this research, many veteran fishermen recalled telling their children that commercial fishing was too financially and physically risky, and that they should have an education and career to fall back on. Somewhat paradoxically, those among today's youth that choose to enter commercial fishing in the future will most likely require the support - financial or otherwise - of their families in order to be successful (Donkersloot et al. in prep). Parental discouragement from pursuing fishing may be reflective of recent ecological and economic crises in Alaska's fisheries (e.g., the 1989 Exxon-Valdez oil spill, the depressed salmon prices in the early 2000s, fish population crashes) and of uncertainty and risk mitigation more generally (Carothers 2008; Donkersloot 2007; Lowe et al. 2012). Youth often internalize the messages that their families send them, even if it seems like
Table 5 Variable importance measures from random forest of community attitude scale. Importance rank based on the mean decrease in mean squared error (MSE) among response values achieved by inclusion of the predictor variable in question in the random forest model

\begin{tabular}{lccc}
\hline Predictor variable & Increase in MSE (\%) & Increase in node purity & Importance rank \\
\hline Region & 0.0027 & 1.07 & 5 \\
Hub/village & 0.0003 & 0.86 & 8 \\
Fishing experience & 0.0010 & 0.85 & 9 \\
Subsistence importance & 0.0054 & 3.30 & 3 \\
Student grew up in community & 0.0031 & 1.74 & 4 \\
Age & 0.0021 & 3.92 & 1 \\
Gender & -0.0001 & 0.97 & 7 \\
Alaska Native identity & 0.0014 & 0.99 & 6 \\
How student feels about life & 0.0073 & 3.78 & 2 \\
\hline
\end{tabular}


Fig. 8 Responses to the survey question: Why might you or another young person not enter commercial fishing? Students were asked to select all that applied; percentages represent the proportion of all responses given

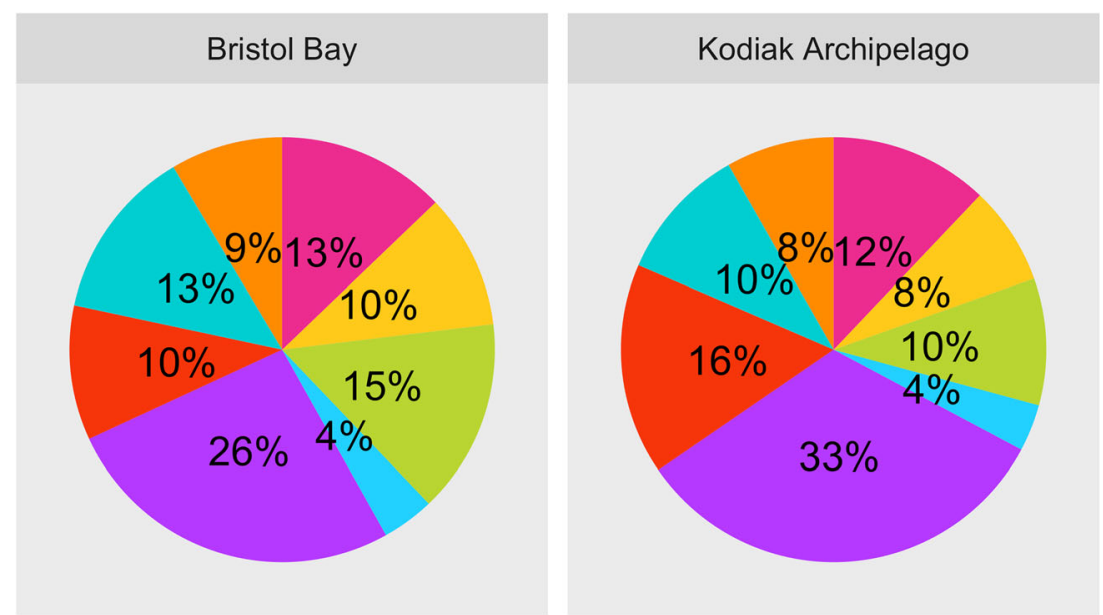

Response
Can make better money doing something else
Costs too much money
Fishermen don't want to hire young people
Fishing jobs are hard to find here
Lack of interest in fishing
No family ties to fishing
Other reasons
Training and skills are hard to find

they do not (Bjarnason and Thorlindsson 2006; Bjarnason 2014). If entire generations of youth have been told that fishing, at worst, is not a worthwhile career or, at best, is very risky, that might explain in part why fewer and fewer young people are entering the fishing industry.

\section{Community Attitudes and Aspirations}

The survey revealed that students' feelings about their communities and their futures are complex and uncertain. In most communities, students expressed ambivalence about life now in their communities, but largely disagreed that the future looked good for young people remaining in the community after high school. Similar feelings of ambivalence have been documented in other rural resource-dependent communities, where employment opportunities in local industrial sectors are attractive to some, but college, military, and other post-high school opportunities are the preferred paths of others (Schafft and Biddle 2015). In this study, smaller communities had higher percentages of students wanting to leave permanently than hub communities, similar to the findings of Hamilton and Seyfrit (1993). The reasons for and patterns in outmigration have been described in detail elsewhere, but in general, rural youth often seek attractive employment, social, recreational, and experiential opportunities that their home communities cannot offer (Bjarnason and Thorlindsson 2006; Bjarnason 2014). Perhaps the most pervasive reason that rural youth across the globe desire to leave their communities is the pressure placed upon them to pursue higher education (Hamilton and Seyfrit 1993; Corbett 2005; White 2015).

Survey respondents expressed a great deal of uncertainty about what their futures will look like, with one exception: $88 \%$ of students said they want to go to college. Accordingly, $79 \%$ of students reported that their parents have encouraged them to attend college. Getting a college degree was both affirmed and challenged in the interview phase of this research as a viable pathway for the next generation of fishermen and for community sustainability in the face youth outmigration. Similarly, Corbett (2013) describes both the "pressure cooker environment" in which youth are pressured to pursue postsecondary education, and the sentiment common in the not-sodistant past that college was wholly unnecessary for a fishing life in the community. One Bristol Bay interview respondent linked regional summer internship programs with drawing local youth 
Fig. 9 Responses to the question: "How would you rate your subsistence fishing activity over the past few years?"

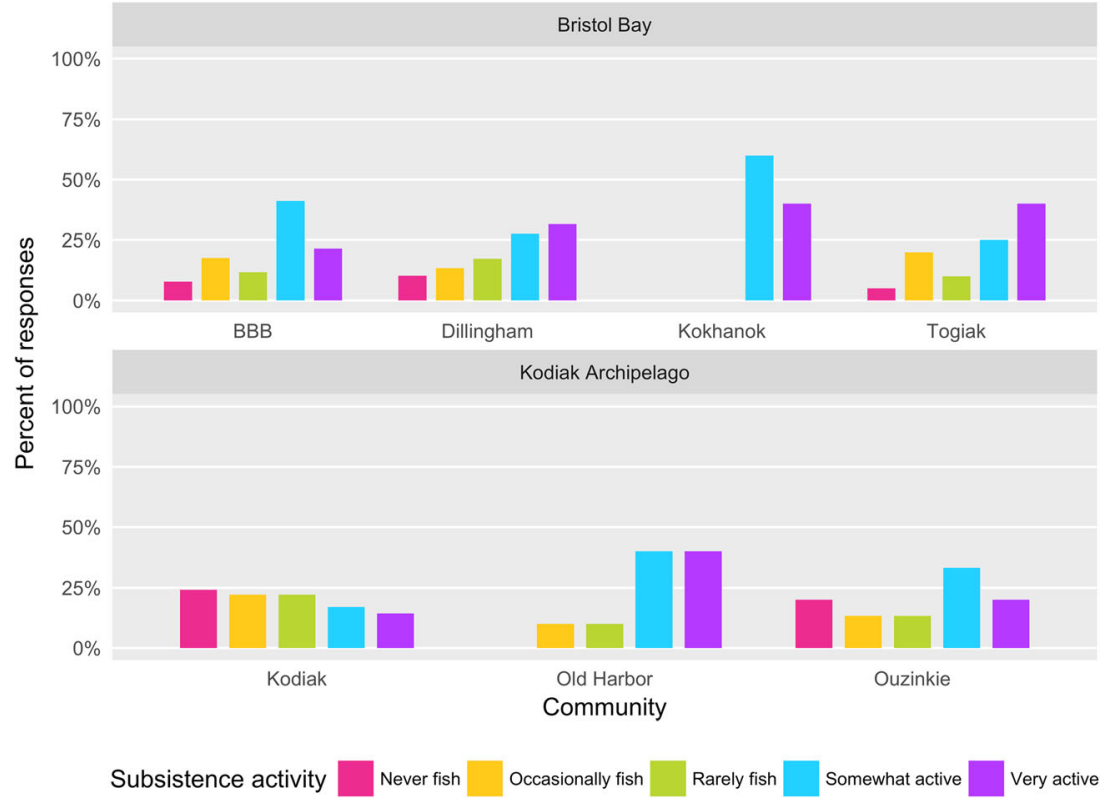

away from fishing jobs, essentially asking youth to choose between a guaranteed hourly wage for the summer and a less-certain, but possibly better-paying share on a fishing boat or site. When youth do decide to leave fishing communities, returning is challenged by the difficulty of putting a degree to use in a small town with limited employment opportunities and by the social ties formed during college years that cement youth in their adopted places (Carr and Kefalas 2009).

With each new generation, the post-high school opportunities available to rural youth grow more numerous and diverse. Today, commercial fishing is one of thousands of career and education pathways youth can choose from. Lowe et al. (2012) described the cultural expectation in fishing communities that youth should pursue higher education instead of seeking career opportunities in a declining fishing industry. This expectation is affirmed by our finding that only $11 \%$ of Kodiak Archipelago students have been encouraged to enter commercial fishing by their parents or extended family, while nearly half of Bristol Bay students have been encouraged to enter commercial fishing. A young commercial fisherman from Kodiak described his fishing family parents' mixed support of his career choice:

Interviewer: Did your family encourage you to get into fishing?

Fisherman: Um, the exact opposite in fact. My mom was always telling me to go to college and my dad always told me he regretted not going to college, but I think my dad was - they were both supportive, but they were both leery of my decisions.

Another important consideration in the degree to which youth are encouraged or discouraged to pursue commercial fishing careers is that participating in Bristol Bay's short salmon season is relatively compatible with college or non-fishing employment, which is not true of most other fisheries, like halibut and sablefish fisheries in the Kodiak Archipelago region. Even so, committing fully to a fishing career is a choice that students in this study were not ready to make. Previous research attributes some of the uncertainty faced by coastal youth in the Gulf of Alaska to the uncertainty and social disruption resulting from fisheries access privatization, single-sector rural economies, and resource and market instability, which have been translated to youth through daily interactions in the community and dinner-table conversations (Lowe 2015; Carothers 2015).

Old Harbor and Ouzinkie, villages in the Kodiak Archipelago study region, provide examples of the link between youth outlook on their communities and the level of fishing engagement in the community. We found that most youth in Ouzinkie do not see a future for themselves there, while Old Harbor students were more optimistic about opportunities available to them if they were to stay beyond graduation (Fig. 7). Previous research has documented the dramatic decrease in fishing participation in both communities over the past generation, but this reduction has been especially severe in Ouzinkie, where only a couple of fishing boats remain active (Carothers 2010). Without a viable commercial fishing economy in Ouzinkie, adults and youth express concern for community sustainability. Accordingly, $83 \%$ of Ouzinkie students disagreed with the statement "my parents/family would prefer if I settled [in Ouzinkie]." Ouzinkie, Old Harbor, and many other communities throughout the Gulf of Alaska have actively fought for the repatriation of their fishing rights for the past several decades, with some initial success (e.g., the creation of the Community Quota Entity Program in the mid2000s), but so far, these efforts have failed to generate a 
reversal of the trend of loss (Carothers 2011; Cullenberg et al. 2017). Continued access to fishing opportunities by local residents is critical in sustaining coastal communities culturally, socially, and economically (Clay and Olson 2008), and research has linked community health to the ability of residents to live meaningful and fulfilling lives in their communities (e.g., Martin 2012).

\section{Limitations}

Comparisons between hub and village communities were difficult to make in this study (and should be interpreted with extreme caution) because of the inherent imbalance in sample sizes resulting from non-random, non-stratified sampling of communities. In other words, small absolute numbers of students from village communities were sampled relative to the hub communities, due in part to the disparity in population between villages and hubs. In comparing the two study regions, differences with respect to each of the attitude scales were statistically significant. However, when viewed in the context of other factors such as family ties to or engagement in fishing, region and community size were not significant predictors of either fishing or community attitude. A stratified random sampling scheme in which communities were stratified by population size to include a greater number of villages would, in future applications of these methods, provide greater insight into how attitudes differ by community size and between fishery-dependent regions.

\section{Conclusions}

Exposure to, engagement in, and family ties to fishing are important predictors of positive fishing attitude, and they are critical for sustaining new entry into fishing. However, there are very real obstacles to converting youth engagement in fishing into the next generation of career fishermen, some of which are being addressed by other programs (e.g., financial barriers, training, and skills). It is important to note that some influences on youth aspirations, such as changing cultural norms and modes of economic production in the USA, cannot be controlled for by programmatic or policy changes. However, where the local culture is still supportive of fishing livelihoods, and career options are available for those who choose commercial fishing, youth engagement in fishing can be strengthened. Mechanisms are needed to recreate what was taken as natural in past generations: that youth living in coastal fishing communities would be exposed to fishing at an early age, and that commercial fishing could provide a good living - one that is place-based, culturally relevant, and economically viable. As fisheries access policies in Alaska and around the globe move increasingly towards privatized fishery rights and exclusion of small-scale fishery operations, fishing livelihoods and the critical periods of exposure to fishing during the childhoods of coastal youth will become fewer and farther between.

This study suggests there are further questions about how best to reconnect youth with fishing opportunities. In Alaska's limited entry fisheries, educational permits are specifically set aside for youth education and training, and are available for use by schools and other organizations with provisions for recouping expenses through sale of commercially caught fish (5 AAC 93.200). Programs such as the Maine lobster fishery's student licensing and apprenticeship programs, while not motivated strictly by promoting local youth entry, serve to formalize engagement in and exposure to fishing, thus opening opportunities to youth who may not possess strong family ties to fishing (Alden and Brewer 2000). Apprenticeships may also provide benefits for rights-holders looking to build trust and share knowledge with an enterprising fisherman to which they may formally transfer rights in the future under negotiated terms. Less-structured programs designed for youth under the age of 18 may include commercial fishing camps, school curricula, or after-school programs (e.g., one modeled after the Future Farmers of America program). Legislation is currently moving through Congress that would, if passed in its current form, allocate funds in the form of three-year grants to regionally focused youth fishery education and training programs, and is potentially a first step towards formalizing fishing engagement and reestablishing commercial fishing as a career pathway in fishing regions of the USA, including coastal Alaskan youth (H.R. 2079 2017; S. 1323 2017).

Youth in coastal communities today are uncertain about their futures. For most, those futures will not include commercial fishing or staying in their communities, in part because job opportunities are limited or have become unattractive, social challenges are problematic, and higher education requires leaving home. Fisheries policy can take a bottom-up approach to attracting future fishing generations by prioritizing and sustaining the connections between fishing livelihoods and coastal communities. Though fisheries management plans at the federal level require consideration of economic and social impacts on fishery-dependent communities, the stated purpose of fisheries management policies in the USA is to conserve marine resources, and to provide the greatest economic benefit in the most efficient way possible to the nation (Clay and Olson 2008). While this is a monumental task filled with trade-offs and compromises between multiple objectives and stakeholders, fishery-dependent communities have been disproportionately burdened in this balancing act (Olson 2011). As fisheries policies continue to disenfranchise small-scale, local fishermen from their livelihoods - including their means of engaging in subsistence and providing for their families - opportunities for youth engagement in the practice, culture, and values of fishing will continue to diminish. The positive feedback loop of fishing 
exposure to the next generation, which depends on a healthy connection between fishing and the community, is strengthened by sustained local access to fishing rights.

Acknowledgments First and foremost, we would like to thank the student participants for their willingness to share their thoughts and opinions in this survey. We appreciate the support of the administration and staff of the Kodiak Island Borough School District, the Lake and Peninsula Borough School District, the Bristol Bay Borough School District, the Dillingham City School District, and the Southwest Region School District that made this research possible. We would also like to thank Meghan Rearden for her help in administering the survey to students in Kokhanok.

Funding Funding for this research was provided by the North Pacific Research Board (Project No. 1323) and Alaska Sea Grant (Project No. R/32-06). Research was conducted under the University of Alaska Fairbanks IRB approval 555479-10.

Open Access This article is distributed under the terms of the Creative Commons Attribution 4.0 International License (http:// creativecommons.org/licenses/by/4.0/), which permits unrestricted use, distribution, and reproduction in any medium, provided you give appropriate credit to the original author(s) and the source, provide a link to the Creative Commons license, and indicate if changes were made.

\section{References}

Alaska Department of Commerce Community and Economic Development (ADCCED). 2017. Alaska Community Database Online.

Alaska Native Heritage Center. 2011. Unangax \& Alutiiq (Sugpiaq) cultures of Alaska. http://www.alaskanative.net/en/main-nav/ education-and-programs/cultures-of-alaska/unangax-and-alutiiq/. Accessed November 28, 2017.

Alden, Robin, and Jennifer F. Brewer. 2000. Apprenticeship and conservation initiatives. In International Institute of Fisheries Economics and Trade IIFET 2000. Corvallis, Oregon.

Apgar-Kurtz, Breena. 2015. Factors affecting local permit ownership in Bristol Bay. Mar Policy 56: 71-77. https://doi.org/10.1016/j.marpol. 2015.02.013.

Argent, Neil, and Jim Walmsley. 2008. Rural youth migration trends in Australia: An overview of recent trends and two inland case studies. Geogr Res 46 (2): 139-152. https://doi.org/10.1111/j.1745-5871. 2008.00505.x.

Bjarnason, Thoroddur. 2014. Adolescent migration intentions and population change: A 20-year follow-up of Icelandic communities. Sociol Rural 54 (4): 500-515.

Bjarnason, Thoroddur, and Thorolfur Thorlindsson. 2006. Should I stay or should I go? Migration expectations among youth in Icelandic fishing and farming communities. J Rural Stud 22 (3): 290-300.

Braund, Sarah Jane. 2017. Set the net: The heritage significance of fish camp and wild salmon in Bristol Bay, Alaska. Doctoral dissertation, University of Montana.

Burnham, Kenneth P., and David R. Anderson. 2002. Model selection and multimodel inference: A practical information-theoretical approach. New York: Springer-Verlag.

Byun, Soo-yong, Judith L. Meece, Matthew J. Irvin, and Bryan C. Hutchins. 2012. The role of social capital in educational aspirations of rural youth. Rural Sociol 77 (3): 355-379. https://doi.org/10. 1111/j.1549-0831.2012.00086.x.

Carothers, Courtney. 2008. Rationalized out: Discourses and realities of fisheries privatization in Kodiak, Alaska. In Enclosing the fisheries: people, places and power. American Fisheries Society Symposium.

Carothers, Courtney. 2010. Tragedy of commodification: Displacements in Alutiiq fishing communities in the Gulf of Alaska. Maritime Studies 9 (2): 95-120.

Carothers, Courtney. 2011. Equity and access to fishing rights: Exploring the community quota program in the Gulf of Alaska. Hum Organ 70 (3): 213-223.

Carothers, Courtney. 2015. Fisheries privatization, social transitions, and well-being in Kodiak, Alaska. Mar Policy 61: 313-322. https://doi. org/10.1016/j.marpol.2014.11.019.

Carr, Patrick J., and Maria J. Kefalas. 2009. The rural brain drain. Chron High Educ 9: 1-13.

Clay, Patricia M., and Julia Olson. 2008. Defining "fishing communities": vulnerability and the magnuson-stevens fishery conservation and management act. Human Ecology Review 15 (2): 143.

Corbett, Michael. 2005. Rural education and out-migration: The case of a coastal community. Can J Educ 28 (1): 52-72. https://doi.org/10. 2307/1602153.

Corbett, Michael. 2013. "I'm going to make sure I'm ready before I leave": The complexity of educational and mobility decisionmaking in a Canadian coastal community. J Rural Stud 32 (1): 275-282.

Cortina, Jose M. 1993. What is coefficient alpha? An examination of theory and applications. J Appl Psychol 78 (1): 98-104.

Cullenberg, Paula, Courtney Carothers, Rachel Donkersloot, Jesse Coleman, and Danielle Ringer. 2017. Turning the tide: How can Alaska address the 'graying of the fleet' and loss of rural fisheries access? Anchorage: University of Alaska Fairbanks.

Donkersloot, Rachel. 2007. Youth emigration and reasons to stay: Linking demographic and ecological change in Bristol Bay, Alaska. In Alaska's fishing communities: Harvesting the future, ed. Paula Cullenberg. Anchorage: Alaska Sea Grant College Program.

Donkersloot, Rachel. 2010. "Now hold on, my attachment to this place is home. That's it.": The politics of place and identity in an Irish fishing locale. Maritime Studies 9 (2): 31-52.

Donkersloot, Rachel, and Courtney Carothers. 2016. The graying of the Alaskan fishing fleet. Environment: Science and Policy for Sustainable Development 58 (3): 30-42.

Donkersloot, Rachel, and Charles Menzies. 2015. Place-based fishing livelihoods and the global ocean: The Irish pelagic fleet at home and abroad. Maritime Studies 14 (1): 1-19.

Fall, James A., Robert J. Walker, Ronald T. Stanek, William E. Simeone, L. Hutchinson-Scarbrough, Philippa Coiley-Kenner, L. Williams et al. 2006. Update of the status of subsistence uses in Exxon Valdez Oil Spill Area communities, 2003, ed. James A. Fall. Anchorage, Alaska: Alaska Department of Fish and Game, Division of Subsistence.

Gho, M., and C. Farrington. 2017. Changes in the distribution of Alaska's commercial fisheries entry permits, 1975-2016. Juneau: Commercial Fisheries Entry Commission.

Glendinning, Anthony, Mark Nuttall, Leo Hendry, Marion Kloep, and Sheila Wood. 2003. Rural communities and well-being: A good place to grow up? Sociol Rev 51 (1): 129-156.

Hamilton, Lawrence C., and Carole L. Seyfrit. 1993. Town-village contrasts in Alaskan youth aspirations. Arctic 46 (3): 255-263.

Hébert, Karen. 2015. Enduring capitalism: Instability, precariousness, and cycles of change in an Alaskan salmon fishery. Am Anthropol 117 (1): 32-46.

Himes-Cornell, Amber, and Kristin Hoelting. 2015. Resilience strategies in the face of short-and long-term change: Out-migration and fisheries regulation in Alaskan fishing communities. Ecol Soc 20 (2): 9. 
Holen, Davin. 2009. The dynamic context of cultural and social sustainability of communities in Southwest Alaska. Journal of Enterprising Communities: People and Places in the Global Economy 3 (3): 306316.

Holen, Davin. 2014. Fishing for community and culture: The value of fisheries in rural Alaska. Polar Record 50 (04): 403-413.

H.R. 2079. 2017. Young Fishermen's Development Act. US House of Representatives, 115th Congress.

Knapp, Gunnar. 2011. Local permit ownership in Alaska salmon fisheries. Mar Policy 35 (5): 658-666.

Langdon, Steve J. 1980. Transfer patterns in Alaskan limited entry fisheries: Final report for the limited entry study group of the Alaska State Legislature.

Lowe, Marie E., Meghan Wilson, Robyn Miller, and Kate Sanders. 2012. Alaska coastal community youth and the future. Report prepared for the Alaska Sea Grant College Program. Anchorage: Institute of Social and Economic Research.

Lowe, Marie E. 2015. Localized practices and globalized futures: Challenges for Alaska coastal community youth. Maritime Studies 14 (1): 1-25. https://doi.org/10.1186/s40152-015-0024-y.

Lumley, Thomas. 2011. Complex surveys: A guide to analysis using $R$. Hoboken: Wiley.

Martin, Stephanie. 2012. Cultural continuity and communities and wellbeing. Journal of Rural and Community Development 7 (1): 74-92.

National Marine Fisheries Service. 2017. 2015 commercial fishery landings by port ranked by dollars. NMFS Commercial Fishery Statistics: Annual Landings. https://www.st.nmfs.noaa.gov/pls/ webpls/MF_LPORT_YEARD.RESULTS. Accessed 6 November 2017.

Olson, Julia. 2011. Understanding and contextualizing social impacts from the privatization of fisheries: An overview. Ocean and Coastal Management 54 (5): 353-363.

Panelli, Ruth. 2002. Young rural lives: Strategies beyond diversity. $J$ Rural Stud 18 (2): 113-122.

Petterson, John S. 1983. Policy and culture - the Bristol Bay Case. J Coast Zone Manag 10 (4): 313-330. https://doi.org/10.1080/ 08920758309361926.

Poppel, Birger. 2006. Interdependency of subsistence and market economies in the Arctic. In The Economy of the North, ed. Solveig Glomsrød and Julie Aslaksen, 65-80. Oslo: Statistics Norway.

Power, Nicole G., Moss E. Norman, and Kathryne Dupré. 2014. "The fishery went away": The impacts of long-term fishery closures on young people's experience and perception of fisheries employment in Newfoundland coastal communities. Ecol Soc 19 (3): 6 .
R Core Team. 2017. R: A language and environment for statistical computing. Vienna: R Foundation for Statistical Computing.

Reedy-Maschner, Katherine. 2009. Entangled livelihoods: Economic integration and diversity in the Western Arctic. Alaska Journal of Anthropology 7 (2): 135-146.

Reedy-Maschner, Katherine L. 2007. The best-laid plans: Limited entry permits and limited entry systems in eastern Aleut culture. Hum Organ 66 (2): 210-225. https://doi.org/10.17730/humo.66.2. 97231040w8jt857n.

Rérat, Patrick. 2014. The selective migration of young graduates: Which of them return to their rural home region and which do not? J Rural Stud 35: 123-132.

Revelle, William. 2007. Experimental approaches to the study of personality. In Handbook of research methods in personality psychology, ed. R.W. Robins, R.C. Fraley, and R.F. Krueger, 37-61. New York: Guilford Press.

Rizopoulos, Dimitris. 2006. 1tm: An R package for latent variable modeling and item response analysis. J Stat Softw 17 (5): 25. https://doi. org/10.18637/jss.v017.i05.

S. 1323. 2017. Young Fishermen's Development Act. US Senate, 115th Congress.

Schafft, Kai, and Catharine Biddle. 2015. Opportunity, ambivalence, and youth perspectives on community change in Pennsylvania's Marcellus Shale region. Hum Organ 74 (1): 74-85.

Tavakol, Mohsen, and Reg Dennick. 2011. Making sense of Cronbach's alpha. Int J Med Educ 2: 53-55.

US Census Bureau. 2016. DP05 - ACS demographic and housing estimates. 2011-2015 American community survey 5-year estimates. https://factfinder.census.gov/faces/nav/jsf/pages/index.xhtml. Accessed 15 December 2016.

US Census Bureau. 2017. DP-1 - profile of general population and housing characteristics: 2010. Decennial Census. https://factfinder. census.gov/faces/nav/jsf/pages/index.xhtml. Accessed 12 November 2017.

van Buuren, Stef, and Karin Groothuis-Oudshoorn. 2011. Mice: Multivariate imputation by chained equations in R. J Stat Softw 45 (3): 67. https://doi.org/10.18637/jss.v045.i03.

White, Carole Sandrine. 2015. Getting into fishing: Recruitment and social resilience in north Norfolk's 'Cromer Crab' fishery, UK. Sociol Rural 55 (3): 291-308.

Publisher's Note Springer Nature remains neutral with regard to jurisdictional claims in published maps and institutional affiliations. 